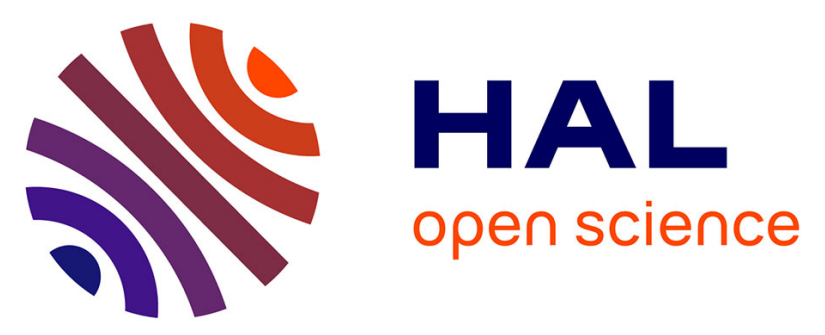

\title{
A Combined Experimental and Computational Study of the LAPCAT II Supersonic Combustor
}

Axel Vincent-Randonnier, Arnaud Ristori, Vladimir Sabelnikov, Niklas

Zettervall, Christer Fureby

\section{To cite this version:}

Axel Vincent-Randonnier, Arnaud Ristori, Vladimir Sabelnikov, Niklas Zettervall, Christer Fureby. A Combined Experimental and Computational Study of the LAPCAT II Supersonic Combustor. 22nd AIAA International Space Planes and Hypersonics Systems and Technologies Conference, Sep 2018, Orlando, United States. 10.2514/6.2018-5208 . hal-02420953

\section{HAL Id: hal-02420953 https://hal.science/hal-02420953}

Submitted on 20 Dec 2019

HAL is a multi-disciplinary open access archive for the deposit and dissemination of scientific research documents, whether they are published or not. The documents may come from teaching and research institutions in France or abroad, or from public or private research centers.
L'archive ouverte pluridisciplinaire HAL, est destinée au dépôt et à la diffusion de documents scientifiques de niveau recherche, publiés ou non, émanant des établissements d'enseignement et de recherche français ou étrangers, des laboratoires publics ou privés. 


\title{
A Combined Experimental and Computational Study of the LAPCAT II Supersonic Combustor
}

\author{
A. Vincent-Randonnier ${ }^{\ddagger, 1}$, A. Ristor ${ }^{\ddagger, 2}$, V. Sabelnikov ${ }^{\ddagger, 3,3}$, N. Zettervall ${ }^{\dagger, 4}$ \& C. Fureby ${ }^{\dagger, 5}$ \\ ONERA - The French Aerospace Lab., F-91761 Palaiseau, \\ ${ }^{\S}$ Central Aerohydrodynamic Institute (TsAGI), 140180 Zhukovsky, Moscow Region, Russia, \\ 'The Swedish Defense Research Agency - FOI, SE 14725 Tumba, Stockholm, Sweden
}

\begin{abstract}
Dual-mode ramjet propulsion systems are suggested for the next generation high-speed flight vehicles. Here, we combine experimental measurements of high-speed (subsonic and supersonic) combustion at different operating conditions in the LAPCAT-II dual-mode ramjet combustor with Large Eddy Simulations (LES) using finite rate chemistry models and new skeletal $\mathrm{H}_{2}$-air combustion chemistry. The LAPCAT II combustor consists of four sections, and experiments have been performed for wall injection of $\mathrm{H}_{2}$ in a Ma 2.0 vitiated airflow for total pressures and temperatures of $p_{0}=0.40 \mathrm{MPa}, 1414 \mathrm{~K}<\mathrm{T}_{0}<1707 \mathrm{~K}$, and a fixed equivalence ratio of $\phi=0.15$. For this $p_{0}$ the combustor is over-expanded, and the transition from supersonic to subsonic flow occurs at the start of the fourth combustor section. The flow and combustion diagnostics include measurements of $p_{0}$ and $T_{0}$ upstream of the combustor, wall-pressure profiles and Schlieren and $\mathrm{OH}^{*}$ chemiluminescence imaging. The computational set-up consists of the full combustor, from the nozzle to the dump-tank. The computational model is composed of a compressible finite rate chemistry LES model, using the mixed subgrid flow model and the Partially Stirred Reactor (PaSR) combustion model, together with a new 22 step $\mathrm{H}_{2}$-air reaction mechanism. Qualitative as well as quantitative comparisons between experiments and simulations show reasonable agreement, but also reveal a high sensitivity of both the LES predictions and the experiments to $T_{0}$. The LES results are further used to describe the underlying mechanisms of flow, wall-injection, mixing, self-ignition and turbulent combustion, and how these interrelated processes are modified by increasing the total temperature under otherwise identical conditions.
\end{abstract}

\section{Introduction and Background}

To reach hypersonic speeds from the ground for aerospace planes, space access vehicles and military aircraft or missiles, a combined-cycle engine approach is often considered needed. Two approaches have been proposed: Rocket-Based Combined-Cycle (RBCC) engines (i.e. a combination of a scramjet flow-path with an embedded rocket engine), operated in either ejector-jet, ramjet, scramjet or rocket modes, under increasing Ma numbers, [1], and Turbine-Based Combined-Cycle (TBCC) engines (a combination of a scramjet flow-path with embedded jet engines), operated in jet-engine, ramjet and scramjet modes, [2]. The most critical features of combinedcycle-enabling combustion technologies are mode transition from the low-speed propulsion system to the highspeed propulsion system, and the subsequent transition from ramjet to scramjet combustion modes. Additional challenges include transonic aero-propulsion performance, high Ma-number jet engine technology development, advanced turbine-based combined cycle integration and innovative 3D flow-path concepts.

In this study, we will consider the transition from ramjet to scramjet combustion modes. In a ramjet, the flow is subsonic as it approaches the combustor, whereas in a scramjet the flow remains supersonic through the combustor. The dual-mode scramjet bridges the gap between the ramjet and scramjet, using the same combustor

\footnotetext{
${ }_{2}^{1}$ Research Scientist, ONERA - The French Aerospace Lab., F-91761 Palaiseau, France.

2 Research Scientist, ONERA - The French Aerospace Lab., F-91761 Palaiseau, France.

3 Research Scientist, ONERA - The French Aerospace Lab., F-91761 Palaiseau, France and Research Scientist, Central Aerohydrodynamic Institute (TsAGI), 140180 Zhukovsky, Moscow Region, Russia.

${ }_{5}^{4}$ Researcher, Defense Security Systems Technology, SE 14725 Tumba, Stockholm, Sweden.

${ }^{5}$ Research Director, Defense Security Systems Technology, SE 14725 Tumba, Stockholm, Sweden, Associate fellow.
} 
for both combustion modes but operating with a thermal throat in the ramjet mode. This may theoretically enable a vehicle to operate from $\mathrm{Ma} \approx 3$ to $\mathrm{Ma} \approx 8$ with only minor engine modifications. At the lower limit of this envelope, the engine operates in ramjet mode. In this mode, combustion heat-release can drive the supersonic inflow to sonic conditions, using thermal choking, whereby a pre-combustion shock-train forms in the isolator. The isolator is placed upstream of the combustor to reduce the interaction between the intake and combustor flow fields, and to prevent intake unstart. The isolator shock-train consists of a series of shocks, which terminate with a normal shock that drives the flow to subsonic conditions. The pre-combustion shock-train aids flame stabilization by increasing the static pressure and temperature whilst decelerating the flow. The pre-combustion shock-train and heat-release are strongly coupled. However, as described in Heiser \& Pratt, [3], at speeds approaching Ma 6, pressure losses associated with the choking increase, and operational efficiency decreases. At Ma 6, the combustion heat-release can be reduced by minor flow-path modifications, or reducing the fuel massflow rate. The dual-mode scramjet then operates in the scramjet mode, in which combustion occurs at supersonic speeds. Transition from subsonic to supersonic combustion is essentially obtained by controlling the heatrelease so that thermal choking is inhibited. Once the heat-release is reduced, the flow is no longer choked and the flow through the combustor remains essentially supersonic. For supersonic combustion the main challenges are to inject, mix, ignite and burn the fuel within the short combustor residence time.

A relatively large number of experimental dual-mode scramjet combustor studies have been reported, e.g. [4-10], using direct-connect vitiated-air facilities with oxygen $\left(\mathrm{O}_{2}\right)$ replacement, conventional wall-pressure measurements and optical access to facilitate Schlieren and/or $\mathrm{OH}^{*}$ chemiluminescence. Some of these studies focus on fundamental as aspects such as the combustion characteristics at different stages of the transition, e.g. [7, 9-10], whereas other are somewhat more applied, e.g. [5, 8], considering models of different flight-vehicles. The general conclusion of these experimental investigations is that the transition process is characterized by the dissolution of a pre-combustion shock train in the isolator, and if the heat addition exceeds a critical value the flow will become thermally choked and the combustor will transition back to ramjet mode, or cause unstart. The specifics of these processes, and how they interact with the flow, compressibility, mixing and combustion processes, are however not well known. Reynolds Averaged Navier-Stokes (RANS) computations have been performed on different dual-mode ramjet combustors, e.g. [11-13], using both finite rate chemistry and flamelet models. The results show strong sensitivity of the predictions to the numerical methods, grids, reaction mechanism as well as the combustion model, and particularly the turbulence model. Large Eddy Simulations (LES) have also been successfully performed on different dual-mode ramjet combustors, e.g., [14-18], using a range of flamelet and finite rate chemistry approaches. Due to the unsteady nature of LES versus RANS, more accurate and useful predictions are generally obtained since the unsteady nature of the shock train in the isolator is a key feature of the dual-mode ramjet engine concept.

In this study we combine experimental investigations of supersonic combustion at different conditions in the LAPCAT-II dual-mode ramjet combustor, [19], with finite rate chemistry Large Eddy Simulation (LES) using skeletal $\mathrm{H}_{2}$-air combustion chemistry. The operating conditions are chosen to be representative of non-reacting, ramjet, dual-mode ramjet and scramjet combustion, respectively. The objectives are to examine transverse mixing, self-ignition, flame stabilization and compressible turbulent combustion, and the dependence of these phenomena on $\mathrm{T}_{0}$ at fixed values of $\phi$ at the different operating conditions. Results from experiments and LES computations will be compared, providing reciprocal validation of the methods, and combined to provide a more comprehensive understanding of the flow, mixing and combustion phenomena occurring under typical dual-mode conditions in this semi-generic combustor.

\section{The ONERA LAERTE Facility and the LAPCAT-II Dual Mode Ramjet Combustor}

For the dual-mode ramjet experiments the ONERA-LAERTE facility is equipped with the LAPCAT-II dualmode ramjet combustor. The facility and the combustor and its operating conditions as well as the measurement procedures have been described in detail in [19]. A schematic of the facility and combustor sections are presented in figures 1a to 1c, and here the facility is operated in the blow-down mode with the combustor acting as a heat-sink. The reference position, $x=0.0 \mathrm{~m}$, corresponds to the throat of the Mach 2.0 nozzle as noted in figure 1c. The combustor width is $40.0 \mathrm{~mm}$ and the inlet height is $35.4 \mathrm{~mm}$. The combustor contains four successive sections: the first has a constant cross-sectional area, whereas the following sections have $1^{\circ}, 3^{\circ}$ and $1^{\circ}$ of diverging half-angles respectively to prevent thermal choking. The combustor length is $1257 \mathrm{~mm}$. Windows are placed at different locations, allowing optical access for either single-point measurements or imaging techniques. 
Experiments were performed for total temperatures, $\mathrm{T}_{0}$, of between $1300 \mathrm{~K}$ and $1800 \mathrm{~K}$, at equivalence ratios, $\phi$, between 0.10 and 0.30 , at a total pressure of $\mathrm{p}_{0}=0.40 \mathrm{MPa}$. All in all, around 50 experimental conditions were tested for different, $\mathrm{T}_{0}$ and $\phi$, resulting in a range of subsonic and supersonic combustion modes and thermal choking. The inflow air-heating was performed by hydrogen air combustion, and oxygen refill. The flow in the combustor is experimentally and computationally observed to be over-expanded, and the transition from supersonic flow to subsonic flow occurs in the far downstream part of the combustor, more specifically in the third combustor section, around $\mathrm{x} \approx 0.75$ to $0.80 \mathrm{~m}$, located in the second window.

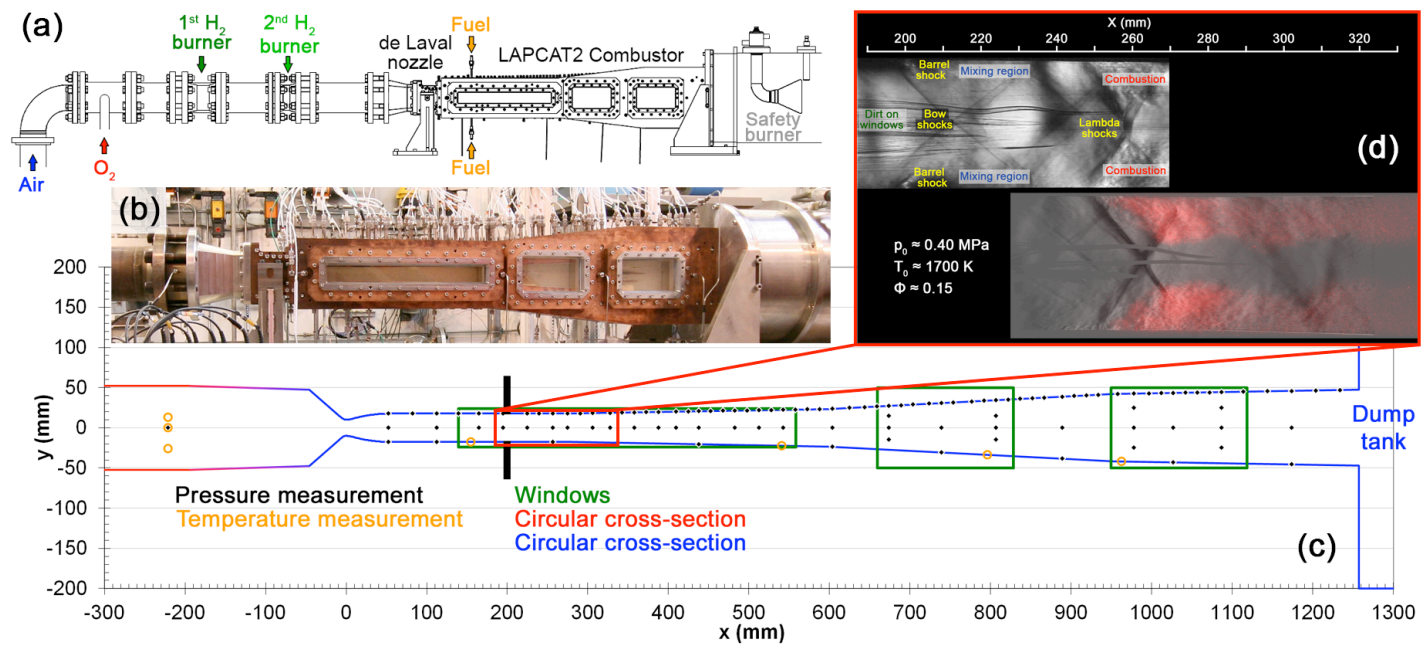

Figure 1. (a) General plan of the LAERTE facility, (b) photo of the LAPCAT-II combustor, (c) geometry of the LAPCAT-II combustor, and (d) combined $\mathrm{OH}^{*}$ chemiluminescence and Schlieren images of representative combustion situations at $\mathrm{T}_{0}=1697 \mathrm{~K}$, cf. Table 1 .

The operating conditions considered in this study focus on the range of observed subsonic and supersonic combustion modes at $\phi \approx 0.15$ and $\mathrm{p}_{0} \approx 0.40 \mathrm{MPa}$ at $\mathrm{T}_{0}$ between $1414 \mathrm{~K}$ and $1720 \mathrm{~K}$. Table 1 list the different case operating conditions $\left(\mathrm{p}_{0}, \phi\right.$ and $\left.\mathrm{T}_{0}\right)$ and the associated inflow air- and fuel mass-flows $\left(\mathrm{m}_{\text {air }}\right.$ and $\left.\mathrm{m}_{\mathrm{H} 2}\right)$ and the related air inflow velocity, $v_{i n}$, temperature, $T_{i n}$, and density, $\rho_{\text {in }}$, as well as the sonic jet-in-crossflow fuel temperature, $\mathrm{T}_{\mathrm{H} 2}$, and density, $\rho_{\mathrm{H} 2}$. The flow and combustion diagnostics include measurements of $\mathrm{p}_{0}$ and $\mathrm{T}_{0}$ upstream of the combustor, pressure profiles along the combustor walls, Schlieren imaging ( $12 \mathrm{kHz}$ at $1 \mu$ s exposure time), and $\mathrm{OH}^{*}$ visualization $(4 \mathrm{kHz}$ at $4 \mu \mathrm{s}$ exposure time) in the three windows in figure $1 \mathrm{c}$. The influence of the heat-soaking combustor material is illustrated by the difference in combustion modes observed in Cases $3 \mathrm{a}$ and $3 \mathrm{~b}$ with the latter case occurring at later operating times, [19].

Table 1. Characteristic properties of the LAPCAT-II combustor simulations.

\begin{tabular}{|c|c|c|c|c|c|c|c|c|c|c|}
\hline Case & $p_{0}[\mathrm{~Pa}] T_{0}[\mathrm{~K}]$ & $n_{\text {air }}[\mathrm{kg} / \mathrm{s}$ & ${ }_{12}[\mathrm{~g} / \mathrm{s}]$ & $\phi$ & $v_{\text {in }}[\mathrm{m} / \mathrm{s}$ & $T_{\text {in }}[K]$ & ${ }_{n}\left[\mathrm{~kg} / \mathrm{m}^{3}\right]$ & ${ }_{12}[\mathrm{~kg} / \mathrm{m}$ & $T_{H 2}[K$ & Combustion \\
\hline 0 & $397740 \quad 1414$ & 0.2931 & 0 & 0 & 686 & 1199 & 0.614 & 0.176 & 294 & Non-reacting \\
\hline 1 & $397740 \quad 1414$ & 0.2931 & 1.53 & 0.15 & 686 & 1199 & 0.614 & 0.176 & 294 & subsonic \\
\hline $3 a$ & 4015501505 & 0.2931 & 1.47 & 0.15 & 707 & 1276 & 0.583 & 0.173 & 297 & unsteady supersonic \\
\hline $3 b$ & 4009001506 & 0.2931 & 1.49 & 0.15 & 708 & 1277 & 0.582 & 0.173 & 299 & thermal choking \\
\hline 4 & 4102201697 & 0.2931 & 1.40 & 0.15 & 751 & 1439 & 0.525 & 0.165 & 306 & shock-induced \\
\hline 5 & 4025501707 & 0.2931 & 1.37 & 0.15 & 754 & 1448 & 0.515 & 0.163 & 304 & shock-induced \\
\hline
\end{tabular}

The combined $\mathrm{OH}^{*}$ chemiluminescence and Schlieren images, figure 1d, provide information about the flow physics and flame stabilization mechanisms, and how these attributes change with operating conditions. The shock-structure and boundary layer separation are very sensitive to $\mathrm{T}_{0}$, and appear to dominate the ignition and flame stabilization mechanisms. For low $\mathrm{T}_{0}$ combustion occurs in the low-speed region in the third combustor section, at midway $\mathrm{T}_{0}$ either unsteady combustion with the combustion fronts oscillating between $\mathrm{x} \approx 0.25 \mathrm{~m}$ and $\mathrm{x} \approx 0.45 \mathrm{~m}$ or thermal choking is observed, and at high $\mathrm{T}_{0}$ shock-induced combustion is observed. 


\section{LES Models, Numerical Methods and Computational Set-Up}

The LES model is based on implicitly-filtered transport equations for mass, momentum, energy and species mass-fractions together with thermal and caloric equations-of-state and constitutive equations, [20-21]. The thermal and caloric equations-of-state are obtained under the assumption of a mixture of thermally perfect gases using tabulated formation enthalpies and specific heats. The constitutive equations are those of a linear viscous mixture with Fickian diffusion and Fourier heat conduction. The viscosity is calculated using Sutherland's law, whereas the thermal conductivity and species diffusivities are computed from the viscosity utilizing constant Prandtl and species Schmidt numbers, respectively, [22]. The unfiltered reaction rates in the filtered species mass-fraction equations results from Guldberg-Waage law of mass-action, involving the summation over all reactions, with reaction rates obtained from Arrhenius rate laws.

The unresolved transport terms, or the subgrid stress tensor and flux vectors, in the filtered transport equations are closed by the mixed model, [23]. The filtered reaction rates are modeled using the Partially Stirred Reactor (PaSR) model, [24-25], which is a multi-scale model based on the observation, [26], that combustion often takes place in dispersed or even intermittent fine-structure regions surrounded by low reaction rates. Here, the filtered reaction rates are modeled as a weighted average of the fine-structure and surrounding reaction rates using the reacting volume fraction, $\gamma^{*}$, as the weighting function. Subgrid mass and energy equations are solved in all LES cells for both the fine-structure and surrounding mass-fractions and temperature, using an estimate of the fine-structures residence time, $\tau^{*}$. In this study, $\tau^{*}$ and $\gamma^{*}$ are modeled using the subgrid, Kolmogorov, and chemical time-scales as detailed in [25]. The LES-PaSR model has been widely used in many different combustion simulations, and is validated for laboratory combustors, [27-28], afterburners, [29], gas turbine combustors, [30], and scramjet combustors, [31-32].

The LES-PaSR model equations are solved using a fully-explicit finite-volume code based on the OpenFOAM C++ library, [33]. High-order monotonicity-preserving reconstruction of the convective fluxes and central differencing of the diffusive fluxes, [34], are combined with a total variation diminishing based RungeKutta time integration scheme to result in a second-order accurate algorithm. The chemical source terms in the species transport equations are evaluated using an operator-splitting approach together with a stiff Rosenbrock solver, [35]. The code is density based, fully compressible, and stability is imposed using compact stencils and by enforcing conservation of kinetic energy with a Courant number limitation of 0.5 .

The computational set-up is shown in figure 2, and starts at the de Laval nozzle and ends in the dump tank before the exhaust water-cooling. Hex-dominant grids with $\sim 26$ and $\sim 77$ million cells, refined along the walls and in the vicinity of the injectors and the downstream plume are used. The Index of Quality, [36], was used to assess the sensitivity of the solution to the grid, and reveals that $87 \%$ and $93 \%$ of the kinetic energy was resolved, respectively, rendering both grids suitable for LES. The lowest values of LESIQ occur in the highspeed injector flow. Dirichlet boundary conditions are used for all variables at the inlet, and at the sonic $\mathrm{H}_{2}$-injectors. Moreover, at the outlet, a wave-transmissive boundary condition is used, [37], given a dump-pressure of $1.0 \mathrm{bar}$, and a no-slip subgrid wall-model, [38], is employed to model the near-wall flow. The grid is adapted to the wall model, and uses $\mathrm{y}^{+}$values of between 40 and 100 . The measured wall temperature is used to provide an estimate of the LES wall temperature of $700 \mathrm{~K}$.

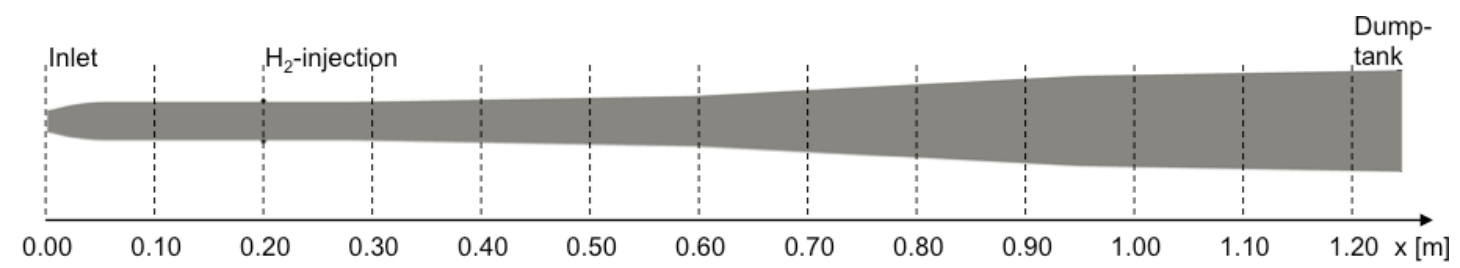

Figure 2. Outline and computational set-up of the LAPCAT II combustor in the ONERA LAERTE facility including key features such as upper and lower inlet, outlet and $\mathrm{H}_{2}$-injection portholes.

\section{IV. $\mathrm{H}_{2}$-Air Combustion Chemistry}

The $\mathrm{H}_{2}$-air combustion process is here modeled using a novel $\mathrm{H}_{2}$-air reaction mechanism that employs the $\mathrm{H}_{2}-\mathrm{O}_{2}$ chemical structure from [39], with three additional fuel breakdown reactions from [40-42], creating a reaction mechanism called Z22, of 9 species and 22 irreversible reactions, listed in Table 2. Hereafter, all reactions are referenced with their reaction numbers in Table 2 . 
In the $\mathrm{H}_{2}-\mathrm{O}_{2}$ chemistry the chain-branching reaction $\mathrm{R} 4$, competes with the chain-propagating reaction R12. R4 effectively creates a pool of radicals decreasing the ignition time, whereas the hydroperoxyl $\left(\mathrm{HO}_{2}\right)$ producing reaction R12 constrains the chain-branching nature of the chemistry, effectively increasing the ignition time. The competition between $\mathrm{R} 4$ and $\mathrm{R} 12$, and the distribution of the fast radicals $\mathrm{O}, \mathrm{H}$ and $\mathrm{OH}$, and slow radical $\mathrm{HO}_{2}$, is very temperature dependent, and produce a region of rapid ignition, (chain-branching explosion at high temperatures), a region of slow ignition (thermal explosion at low temperatures), and a connecting region. This intermediate temperature region, the so-called crossover region, is dominated by complex chemistry, and is also where many ram-, scram- and dual mode ramjet engines typically operate. Having a chemical kinetic able to reproduce the ignition behavior in this region is important for the predictability of the ignition, flame anchoring and subsequent flame-stabilization in these engines.

The reaction mechanism Z22 includes reactions important for the complete temperature spectrum, above and below the crossover region. At high temperatures the branched-chain explosion, and its associated ignition delay, can be well described using reactions R1, R4, R5, R8 and R12, [43].

As the temperature and subsequently the chain-branching reactions, decreases, new chain-propagating reaction paths become rate limiting. At lower temperatures, when $\mathrm{R} 12$ competes favorably with $\mathrm{R} 4$, the $\mathrm{HO}_{2}$ concentration increases. This enhances the importance of alternative reaction routes, mainly via reaction $\mathrm{R} 16$ and R20, which will increase the $\mathrm{H}_{2} \mathrm{O}_{2}$ concentration. The main consumption route of $\mathrm{H}_{2} \mathrm{O}_{2}$ in $\mathrm{Z} 22$ is through reaction $\mathrm{R} 17$, creating two $\mathrm{OH}$ radicals that will react further mainly via reaction $\mathrm{R} 8$, [43], in turn creating a $\mathrm{H}$ radical. In Z22 it is essential to increase the occurrence of reaction R17 by lowering of the activation energy in order to achieve a lowered ignition delay time at and below the crossover region.

Table 2. The Z22 reaction mechanism $\left(\mathrm{k}=\mathrm{A} \cdot \mathrm{T}^{\mathrm{n}} \cdot \exp \left(-\mathrm{E}_{\mathrm{a}} / \mathrm{RT}\right)\right.$, units: $\mathrm{s}$, mole, $\left.\mathrm{cm}^{3}, \mathrm{cal}, \mathrm{K}\right)$.

\begin{tabular}{|c|c|c|c|c|c|}
\hline$\#$ & Reaction & A & $\mathrm{N}$ & $\mathrm{E}_{\mathrm{a}}$ & Ref. \\
\hline 1 & $\mathrm{H}_{2}+\mathrm{O}_{2} \rightarrow \mathrm{H}+\mathrm{HO}_{2}$ & $7.40 \mathrm{E}+05$ & 2.43 & 53500 & [41] \\
\hline 2 & $\mathrm{H}_{2}+\mathrm{M} \rightarrow \mathrm{H}+\mathrm{H}+\mathrm{M}$ & $4.57 \mathrm{E}+19$ & -1.4 & 105100 & [40], c \\
\hline 3 & $\mathrm{HO}_{2}+\mathrm{H}_{2} \rightarrow \mathrm{H}_{2} \mathrm{O}_{2}+\mathrm{H}$ & $3.00 \mathrm{E}+06$ & 2 & 21000 & [42] \\
\hline 4 & $\mathrm{H}+\mathrm{O}_{2} \rightarrow \mathrm{OH}+\mathrm{O}$ & $2.45 \mathrm{E}+14$ & 0 & 16800 & [39], a \\
\hline 5 & $\mathrm{OH}+\mathrm{O} \rightarrow \mathrm{H}+\mathrm{O}_{2}$ & $1.20 \mathrm{E}+13$ & 0 & 690 & [39] \\
\hline 6 & $\mathrm{O}+\mathrm{H}_{2} \rightarrow \mathrm{OH}+\mathrm{H}$ & $1.80 \mathrm{E}+10$ & 1 & 8826 & [39] \\
\hline 7 & $\mathrm{OH}+\mathrm{H} \rightarrow \mathrm{O}+\mathrm{H}_{2}$ & $8.00 \mathrm{E}+09$ & 1 & 6760 & [39] \\
\hline 8 & $\mathrm{H}_{2}+\mathrm{OH} \rightarrow \mathrm{H}_{2} \mathrm{O}+\mathrm{H}$ & $1.17 \mathrm{E}+09$ & 1.3 & 3626 & [39] \\
\hline 9 & $\mathrm{H}_{2} \mathrm{O}+\mathrm{H} \rightarrow \mathrm{H}_{2}+\mathrm{OH}$ & $5.09 \mathrm{E}+09$ & 1.3 & 18588 & [39] \\
\hline 10 & $\mathrm{OH}+\mathrm{OH} \rightarrow \mathrm{O}+\mathrm{H}_{2} \mathrm{O}$ & $6.00 \mathrm{E}+08$ & 1.3 & 0 & [39] \\
\hline 11 & $\mathrm{O}+\mathrm{H}_{2} \mathrm{O} \rightarrow \mathrm{OH}+\mathrm{OH}$ & $5.90 \mathrm{E}+09$ & 1.3 & 17029 & [39] \\
\hline 12 & $\mathrm{H}+\mathrm{O}_{2}+\mathrm{M} \rightarrow \mathrm{HO}_{2}+\mathrm{M}$ & $1.80 \mathrm{E}+18$ & -0.8 & 0 & [39], a, d \\
\hline 13 & $\mathrm{H}+\mathrm{HO}_{2} \rightarrow \mathrm{OH}+\mathrm{OH}$ & $1.50 \mathrm{E}+14$ & 0 & 1004 & [39] \\
\hline 14 & $\mathrm{H}+\mathrm{HO}_{2} \rightarrow \mathrm{H}_{2}+\mathrm{O}_{2}$ & $2.50 \mathrm{E}+13$ & 0 & 700 & [39] \\
\hline 15 & $\mathrm{OH}+\mathrm{HO}_{2} \rightarrow \mathrm{H}_{2} \mathrm{O}+\mathrm{O}_{2}$ & $2.00 \mathrm{E}+13$ & 0 & 1000 & [39] \\
\hline 16 & $\mathrm{HO}_{2}+\mathrm{HO}_{2} \rightarrow \mathrm{H}_{2} \mathrm{O}_{2}+\mathrm{O}_{2}$ & $8.00 \mathrm{E}+13$ & 0 & 0 & [39] \\
\hline 17 & $\mathrm{H}_{2} \mathrm{O}_{2}+\mathrm{M} \rightarrow \mathrm{OH}+\mathrm{OH}+\mathrm{M}$ & $1.30 \mathrm{E}+17$ & 0 & 34500 & [39], b \\
\hline 18 & $\mathrm{OH}+\mathrm{OH}+\mathrm{M} \rightarrow \mathrm{H}_{2} \mathrm{O}_{2}+\mathrm{M}$ & $9.86 \mathrm{E}+14$ & 0 & -5070 & [39] \\
\hline 19 & $\mathrm{H}_{2} \mathrm{O}_{2}+\mathrm{OH} \rightarrow \mathrm{H}_{2} \mathrm{O}+\mathrm{HO}_{2}$ & $1.00 \mathrm{E}+13$ & 0 & 1800 & [39] \\
\hline 20 & $\mathrm{H}_{2} \mathrm{O}+\mathrm{HO}_{2} \rightarrow \mathrm{H}_{2} \mathrm{O}_{2}+\mathrm{OH}$ & $2.86 \mathrm{E}+13$ & 0 & 32790 & [39] \\
\hline 21 & $\mathrm{OH}+\mathrm{H}+\mathrm{M} \rightarrow \mathrm{H}_{2} \mathrm{O}+\mathrm{M}$ & $2.20 \mathrm{E}+22$ & -2 & 0 & [39] \\
\hline 22 & $\mathrm{H}+\mathrm{H}+\mathrm{M} \rightarrow \mathrm{H}_{2}+\mathrm{M}$ & $1.80 \mathrm{E}+18$ & -1 & 0 & [39] \\
\hline
\end{tabular}

a: Pre-exponential factor has been modified compared to the cited reference.

b: Activation energy has been modified compared to the cited reference.

c: Collisional coefficients $\mathrm{H}_{2}: 2.5 \quad \mathrm{H}_{2} \mathrm{O}: 12.0 \quad \mathrm{~N}_{2}: 1.0 \quad \mathrm{O}_{2}: 1.0$.

d: Collisional coefficients $\mathrm{H}_{2}: 1.0 \quad \mathrm{H}_{2} \mathrm{O}: 6.5 \quad \mathrm{~N}_{2}: 0.4 \quad \mathrm{O}_{2}: 0.4$.

The mechanism development was performed using the laminar flame speed, $\mathrm{s}_{\mathrm{u}}$, flame temperature, $\mathrm{T}_{\text {flame }}$, and ignition delay time, $\tau_{\text {ign }}$, as targets. Additional effort during the mechanism development was to create a mechanism that could match the ignition delay times in the crossover region. The detailed mechanisms of Alekseev et al., [41], K30, and Jachimowski, [44], J20, the skeletal mechanism of Davidenko \& Gökalp, [45], D7, 
as well as the global mechanism of Marinov et al., [46], M1, are employed for comparisons in combination with experimental data, [47-61], over a pressure range from about $1.0 \mathrm{~atm}$ to $5.8 \mathrm{~atm}$.

Figures $3 \mathrm{a}, 3 \mathrm{~b}$ and $3 \mathrm{c}$ compare predictions and experimental data for $\mathrm{s}_{\mathrm{u}}$ (left axis) and $\mathrm{T}_{\text {flame }}$ (right axis) at $1 \mathrm{~atm}$ and $300 \mathrm{~K}$, and $\tau_{\mathrm{ign}}$ at $1 \mathrm{~atm}$ and $4 \mathrm{~atm}$, respectively. Concerning $\mathrm{s}_{\mathrm{u}}, \mathrm{Z} 22$ is in reasonable agreement with the experimental data and the predictions from $\mathrm{K} 30, \mathrm{~J} 20$ and $\mathrm{M} 1$. For $\mathrm{T}_{\text {flame }}$, all mechanisms produce similar predictions, with the largest deviations at around stoichiometric conditions. For $\tau_{\mathrm{ign}}$ at $1 \mathrm{~atm}$, figure $3 \mathrm{~b}$, all mechanisms performs similarly above $1000 \mathrm{~K}$, but with deviations below. The simplified mechanism, D7 and M1, neglect the $\mathrm{H}_{2} \mathrm{O}_{2}$ and $\mathrm{HO}_{2}$ chemistry, results in inabilities to reproduce the bending of the ignition curve within the crossover region, and with the curves for J20 and K30 predicting higher $\tau_{\text {ign }}$ when the temperature decreases, than Z22. At 4 atm, figure $3 \mathrm{c}$, the limitation in predictions of $\tau_{\text {ign }}$ in the crossover region and below for the different mechanisms compared to Z22 is even more obvious, with either over- or underpredictions of $\tau_{\text {ign }}$ as compared to the data. In addition, Z22 is also the only investigated mechanism able to satisfactorily reproduce the experimental data at the lowest temperatures. Significant differences in $\tau_{\text {ign }}$ below $1000 \mathrm{~K}$ between the mechanisms will critically impact anchoring and stabilization of the flame within the combustor.
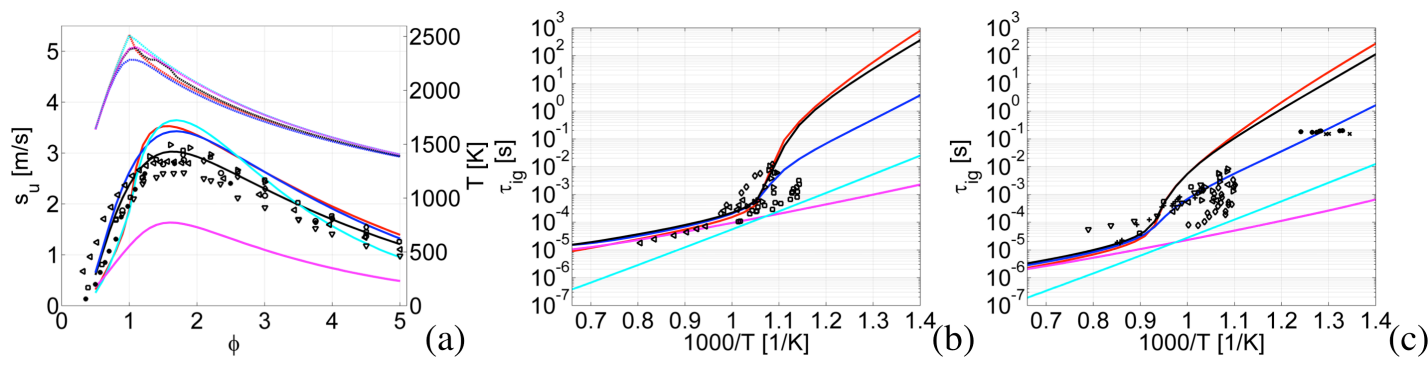

Figure 3. Comparison of (a) laminar flame speeds, $s_{u}$, (left axis) and adiabatic flame temperatures, $\mathrm{T}_{\mathrm{ad}}$, (right axis) at $\mathrm{T}=300 \mathrm{~K}$ and $\mathrm{p}=1 \mathrm{~atm}$, and ignition delay times, $\tau_{\mathrm{ign}}$, at 1 atm (b) and (c) $4 \mathrm{~atm}$, for $\mathrm{H}_{2}$-air mixtures. Legend: (一) M1, [46], (一) Z22, (一) J20, [44], (一) D7, [45], (一) $\mathrm{K} 30$, [41], and experimental data (black symbols) from [47-61].

The reason for the discrepancies between the detailed mechanism predictions and the experimental data below $\sim 1000 \mathrm{~K}$ is a topic under debate, with the issue of non-homogeneous conditions being one criticism of the current way of modeling $\tau_{\text {ign }}$ at low temperatures. Investigators, [56, 62-63], have observed two distinct ignition phenomena depending on the temperature conditions. Z22 is designed to take the possibly non-homogeneous conditions into account when using the standard model for estimating $\tau_{\text {ign }}$, but a secondary approach could be to include a nonhomogeneous condition into $\tau_{\text {ign }}$ when simulating current detailed mechanisms.

\section{Results and Discussion}

The focus of this investigation is to qualitatively and quantitatively examine the turbulent flow, fuel-injection, mixing, self-ignition and subsequent turbulent combustion at or in the vicinity of the operating conditions listed in Table 1, characteristic of dual-mode ramjet operation. A non-reacting case is included to provide a reference for the reactive cases, and to facilitate a discussion about the turbulent flow physics and its interactions with the shock-train in the LAPCAT-II combustor.

\section{V.A. Non-Reacting Supersonic Flow in the LAPCAT-II Combustor}

Figure 4 shows a combination of experimental images and numerical simulation results from the side of the non-reacting flow (Case 0) in the LAPCAT-II combustor (from the nozzle through to the start of the dump tank). The experimental panels show Schlieren images, in original and enlarged formats, obtained around and downstream of the location of $\mathrm{H}_{2}$ injection in the first window. These images reveal a shock-train developing along the first constant area combustor section, continuing through the remaining combustor sections whilst being weakened and modified by the interactions with the wall boundary layer, and by the diverging combustor profile. In the successive enlargements of these images, the bow-, lambda- and barrel shocks are clearly visible as are the associated wakes and plumes (when appropriate) behind these. From these images it is also evident that the wake and plume structures interacts with the wall boundary layer and the shock-train, resulting in modified wall boundary layers and distorted shock structures. The numerical simulation results show from top to 
bottom a superposition of the axial velocity, $\mathrm{v}_{\mathrm{x}}$, and the vorticity, represented by iso-surfaces of the second invariant of the velocity gradient tensor, $\lambda_{2}$, colored by $\mathrm{v}_{\mathrm{x}}$, the temperature, $\mathrm{T}$, the heat-release, $\mathrm{Q}$, and finally a superposition of the pressure, $\mathrm{p}$, with the modeled $\mathrm{OH}^{*}$ photon emission rate, $\mathrm{k}_{\mathrm{OH}^{*}}$. The modeled $\mathrm{OH}^{*}$ photon emission rate is obtained as a post-processing step based on the global reaction $\mathrm{H}+\mathrm{O}+\mathrm{M}=\mathrm{OH}^{*}+\mathrm{M}$, with $\mathrm{k}_{\mathrm{OH}^{*}}$ being computed from the product of the resulting $\mathrm{OH}^{*}$ concentration, $\left[\mathrm{OH}^{*}\right]$, and the spontaneous emission rate coefficient of $\left[\mathrm{OH}^{*}\right]$, with rate constants obtained from, [64].

The distribution of $\lambda_{2}$ evolve from the very thin boundary layer in the throat of the nozzle, which start to transition just downstream of the nozzle. Gradually, typical boundary layer vortical structures develop along the walls of the first constant-area combustor section. This braid of boundary layer vortical structures becomes distorted by the wakes and plumes downstream of the bow-, lambda- and barrel shocks which develop just in front of the $\mathrm{H}_{2}$ injectors. In case of $\mathrm{H}_{2}$ injection, a horseshoe-vortex system is also formed around the plume that sweeps downstream parallel too but outside of the plume. The resulting vortical structures develops with downstream distance from the $\mathrm{H}_{2}$ injectors, and in the case of $\mathrm{H}_{2}$ injection, S-shaped side arms develop over the plume that gradually transitions into $\Omega$-shaped vortical structures and then further into longitudinal vortices. Just downstream of the $1^{\circ}$ to $3^{\circ}$ transition, at $0.70<x<0.80(\mathrm{~m})$, the flow separates, and low-speed zones are formed along the upper and lower walls. Separation occurs either along the upper or the lower wall, with the line of separation oscillating back and forth. Furthermore, the separation and associated low-speed zones regularly intermittently change between the upper and lower walls, resulting in an asymmetric flow. No considerable temperature increase, heat-release or modeled $\mathrm{OH}^{*}$ photon emission occurs when no $\mathrm{H}_{2}$ is injected, but with $\mathrm{H}_{2}$ injection ignition occurs in either the upper, lower or both boundary layers in the downstream part of the combustor, the location being dependent on $\mathrm{T}_{0}$. The pressure, $\mathrm{p}$, reveals a distinct shock-train that traverses downstream whilst being distorted and broken-up by the interactions with the wall boundary layers and the bow- lambdaand barrel shocks as well as the plume.
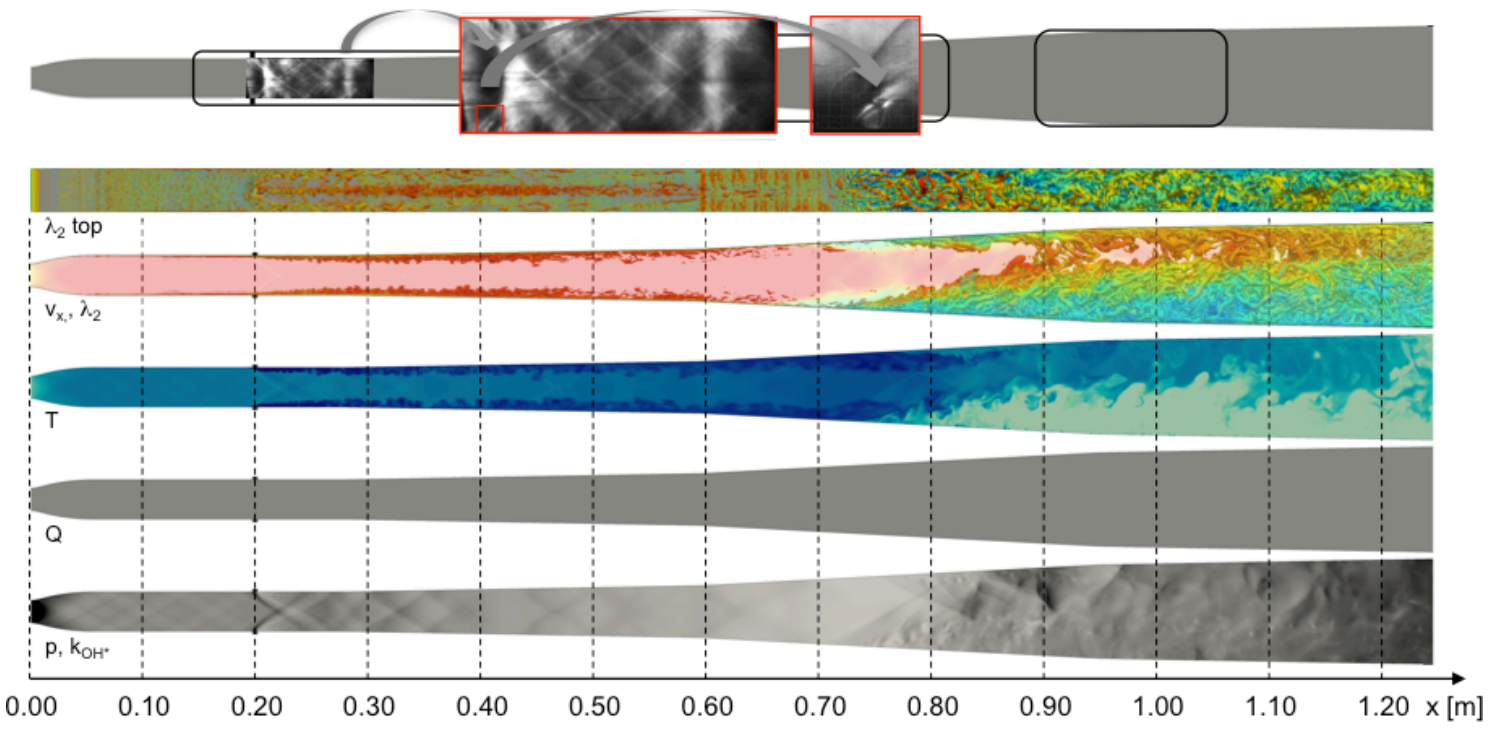

Figure 4. Combined experimental Schlieren image (top) together with computational images of the velocity, $\mathrm{v}_{\mathrm{x}}$, and vorticity, $\lambda_{2}$, from above and from the side, and the temperature, $\mathrm{T}$, heat release, $\mathrm{Q}$, and $\mathrm{OH}^{*}$ photon emission rate, $\mathrm{k}_{\mathrm{OH}^{*}}$, for Case 0 .

\section{V.B. Subsonic and Supersonic Combustion in the LAPCAT-II Combustor}

Figure 5 shows a combination of experimental images and numerical simulation results from the side of Case 1. The experimental panels show spontaneous combustion images, obtained from an ordinary camcorder, showing approximately where combustion takes place at this operating condition. As observed, combustion starts just downstream of the $1^{\circ}$ to $3^{\circ}$ transition, (in the second window) at $0.75<x<0.80 \mathrm{~m}$, and continues further downstream. In addition, the upper and lower flame branches appear dissimilar, with the lower flame branch being noticeably larger and more intense than the upper flame branch. The upper and lower flame branches are however found to alternate from being attached to the upper and lower walls, respectively, resulting in a symmetric mean combustion image. The simulation results show from top to bottom a superposition of contours of $\mathrm{v}_{\mathrm{x}}$, and 
iso-surfaces of $\lambda_{2}$, colored by $\mathrm{v}_{\mathrm{x}}$, contours of $\mathrm{T}$, contours of $\mathrm{Q}$, and finally a superposition of contours of $\mathrm{p}$, with the modeled $\mathrm{OH}^{*}$ photon emission rate.

As for Case 0 the distribution of $\lambda_{2}$ evolve from the very thin boundary layer in the nozzle throat that starts to transition just downstream of the nozzle. The boundary layer continues to develop along the upper and lower combustor walls until separation occurs just downstream of the $1^{\circ}$ to $3^{\circ}$ transition, around $x=0.75 \mathrm{~m}$. After $\mathrm{H}_{2}$ injection the upper and lower boundary layers are severely distorted by the $\mathrm{H}_{2}$ rich plumes that are aligned by $\mathrm{S}$-shaped side arms that develop over the plume, and gradually transition into $\Omega$-shaped vortical structures and then further into longitudinal vortices. A horseshoe-vortex system also from around the plume that sweeps downstream parallel too but outside of the plume. The temperature, $\mathrm{T}$, and heat release, $\mathrm{Q}$, distributions show consistent behaviors, with a significant increase in $\mathrm{T}$ following the intense heat-release from the combustion that occurs in the upper and lower wall boundary layers just after separation. By analyzing the modified Takeno Flame Index (TFI), [65], these two flame branches are found to be premixed as the injected $\mathrm{H}_{2}$ and the vitiated air have had sufficient time to mix prior to the ignition that takes place just downstream of the separation. The pressure, $p$, reveals a shock-train that traverses downstream whilst being deformed and broken-up by the interactions with the boundary layers and the bow- lambda, and barrel shocks as well as by the plume. The modeled $\mathrm{OH}^{*}$ photon emission rate, $\mathrm{k}_{\mathrm{OH}^{*}}$, correlates well with $\mathrm{T}$ and $\mathrm{Q}$ as anticipated.

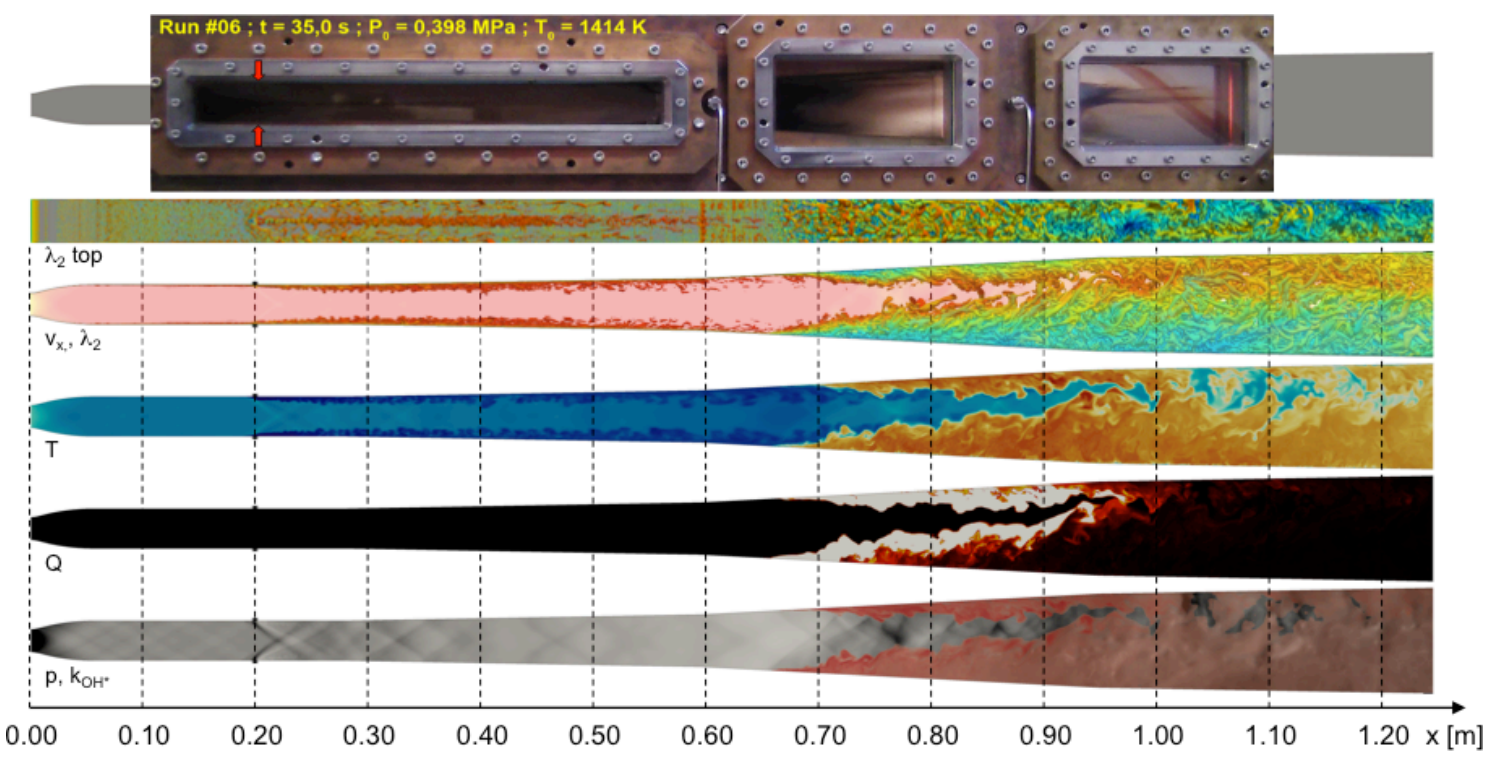

Figure 5. Combined experimental combustion image (top) with computational images of the velocity, $\mathrm{v}_{\mathrm{x}}$, vorticity, $\lambda_{2}$, from above and from the side, and the temperature, $\mathrm{T}$, heat release, $\mathrm{Q}$, and $\mathrm{OH}^{*}$ photon emission rate, $\mathrm{k}_{\mathrm{OH}^{*}}$, for Case 1 .

Figure 6 shows a combination of spontaneous combustion images and numerical simulation results from the side of Case $3 \mathrm{a}$. The numerical simulation results show from top to bottom a superposition of $\mathrm{v}_{\mathrm{x}}$, and isosurfaces of $\lambda_{2}$, colored by $\mathrm{v}_{\mathrm{x}}, \mathrm{T}, \mathrm{Q}$, and a superposition of $\mathrm{p}$, with the modeled $\mathrm{OH}^{*}$ photon emission rate. Both the numerical simulation results and the experimental combustion images reveal that combustion occurs much earlier compared to Case 1, i.e. towards the end of the first constant area combustor section, or in the beginning of the second combustor section, both within first window. The experimental combustion images suggests a rather blunt combustion front, oscillating approximately between $0.30 \mathrm{~m}<\mathrm{x}<0.45 \mathrm{~m}$, whereas the numerical simulations predicts a somewhat more gradual combustion front, oscillating approximately between $0.28 \mathrm{~m}<\mathrm{x}<0.40$ $\mathrm{m}$. Moreover, the numerical simulation suggests that the two (upper and lower) flame branches are relatively loosely coupled and hence behave rather independently.

As for Cases 0 and 1 the distribution of $\lambda_{2}$ evolve from the very thin boundary layer in the nozzle throat that starts to transition just downstream of the nozzle. The boundary layer continues to develop until it is significantly distorted by the combustion occurring in the boundary layer as a consequence of the $\mathrm{H}_{2}$ injection. When the $\mathrm{H}_{2}$ in the plume and in the horseshoe vortex system ignites, the temperature rise, the viscosity increase, the vortex structures thickens, and the topology of the vortex system in the boundary layer and in the plumes 
change, resulting in larger and more frequently occurring $\Omega$-shaped vortical structures and fewer $\mathrm{S}$-shaped side arms. Far downstream longitudinal vortices still dominate. The temperature, T, and heat release, Q, distributions show consistent behaviors with high values of $\mathrm{T}$ and $\mathrm{Q}$ coinciding in the first two sections of the combustor after which the high values of $\mathrm{Q}$ decrease as the $\mathrm{H}_{2}$ is consumed, but with maintained high values of $\mathrm{T}$ in the product composition. The modified TFI, [65], suggests that non-premixed combustion dominate this case. The pressure, $\mathrm{p}$, reveal a shock-train that traverses downstream whilst being deformed and broken-up by the interactions with the boundary layers and the bow- lambda, and barrel shocks as well as the plume. The modeled $\mathrm{OH}^{*}$ photon emission rate, $\mathrm{k}_{\mathrm{OH}^{*}}$, correlate well with $\mathrm{T}$ and $\mathrm{Q}$ as anticipated.

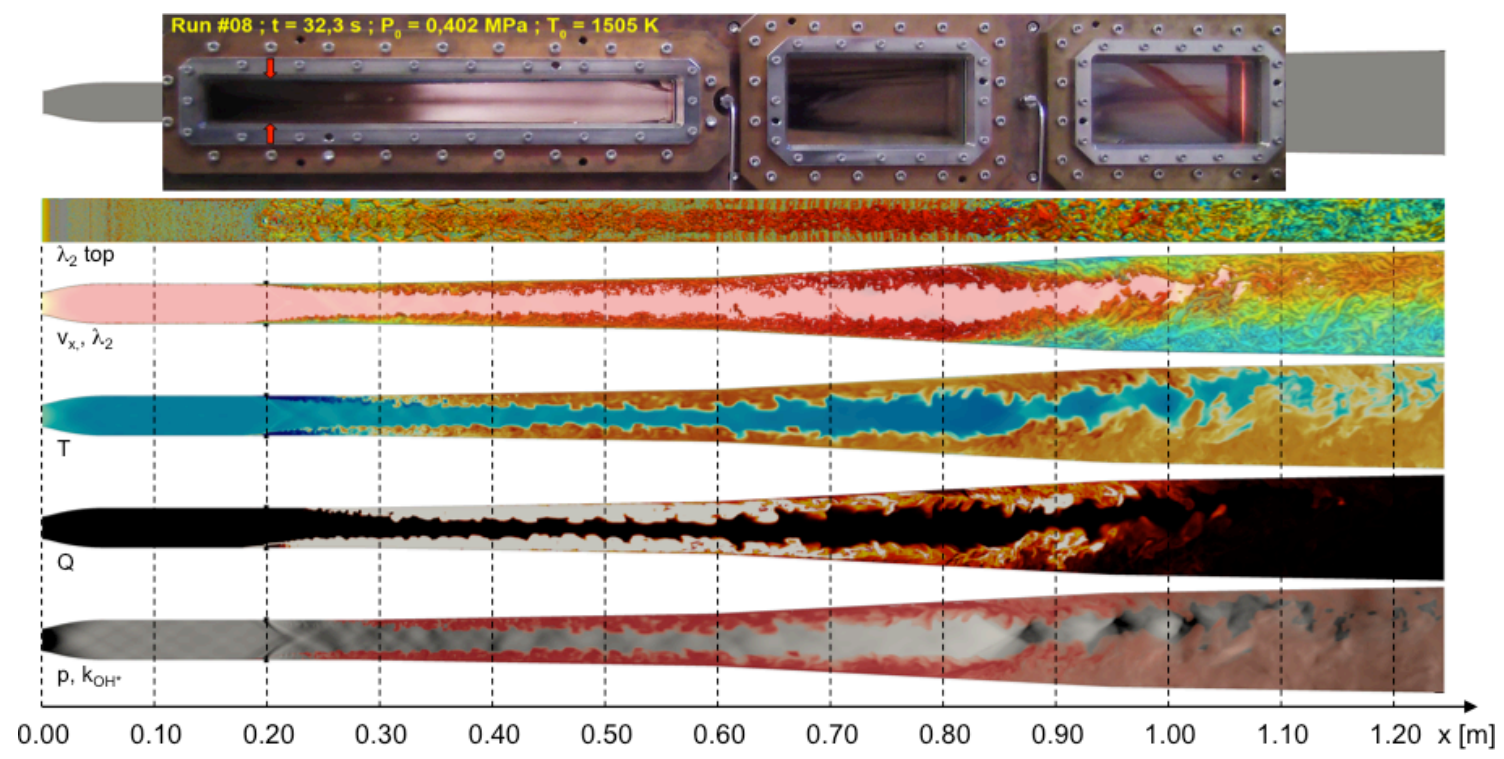

Figure 6. Combined experimental combustion image (top) with computational images of the velocity, $\mathrm{v}_{\mathrm{x}}$, vorticity, $\lambda_{2}$, from above and from the side, and the temperature, $\mathrm{T}$, heat release, $\mathrm{Q}$, and $\mathrm{OH}^{*}$ photon emission rate, $\mathrm{k}_{\mathrm{OH}^{*}}$, for Case $3 \mathrm{a}$.

Figure 7 shows a combination of spontaneous combustion images and numerical simulation results from the side of Case 4. The numerical simulation results show from top to bottom a superposition of $\mathrm{v}_{\mathrm{x}}$, and isosurfaces of $\lambda_{2}$, colored by $\mathrm{v}_{\mathrm{x}}, \mathrm{T}, \mathrm{Q}$, and a superposition of $\mathrm{p}$, with the $\mathrm{OH}^{*}$ photon emission rate. Both the numerical simulation results and the experimental combustion images reveal that combustion takes place even earlier: The $\mathrm{OH}^{*}$ and Schlieren images indicate that combustion starts abruptly at $\mathrm{x} \approx 0.26 \mathrm{~m}$ due to shock-induced ignition, whereas the numerical simulations suggest too early combustion, driven by shock-induced ignition, with intermittent combustion occurring also in front of the injectors, beneath the bow-shocks and partially in the horseshoe vortices surrounding the $\mathrm{H}_{2}$ rich jets. Furthermore, all numerical simulations suggest that the upper and lower flame branches alternate from being attached to the upper and lower walls, respectively, with a frequency of approximately $50 \mathrm{~Hz}$.

As for Cases 0,1 and $3 a$ the distribution of $\lambda_{2}$ evolve from the very thin boundary layer in the nozzle throat that starts to transition just downstream of the nozzle. The boundary layer continues to develop until it is significantly distorted by the combustion occurring in the boundary layer as a consequence of the $\mathrm{H}_{2}$ injection. When the $\mathrm{H}_{2}$ in the plume and in the horseshoe vortex system ignites, the temperature rise, the viscosity increase, the vortex structures thickens, and the topology of the vortex system in the boundary layer and in the plumes change, resulting in larger and more frequently occurring $\Omega$-shaped vortical structures and fewer Sshaped side arms. Far downstream longitudinal vortices still dominate. The temperature, T, and heat release, Q, distributions show consistent behaviors with high values of $\mathrm{T}$ and $\mathrm{Q}$ coinciding in the first two sections of the combustor after which the high values of $\mathrm{Q}$ decrease as the $\mathrm{H}_{2}$ is consumed, but with maintained high values of $\mathrm{T}$ in the product composition. The modified TFI, [65], suggests that non-premixed combustion dominate this case. The pressure, $p$, reveal a shock-train that traverses downstream whilst being deformed and broken-up by the interactions with the boundary layers and the bow- lambda, and barrel shocks as well as the plume. The estimated $\mathrm{OH}^{*}$ photon emission rate, $\mathrm{k}_{\mathrm{OH}^{*}}$, correlate well with $\mathrm{T}$ and $\mathrm{Q}$ as anticipated. 


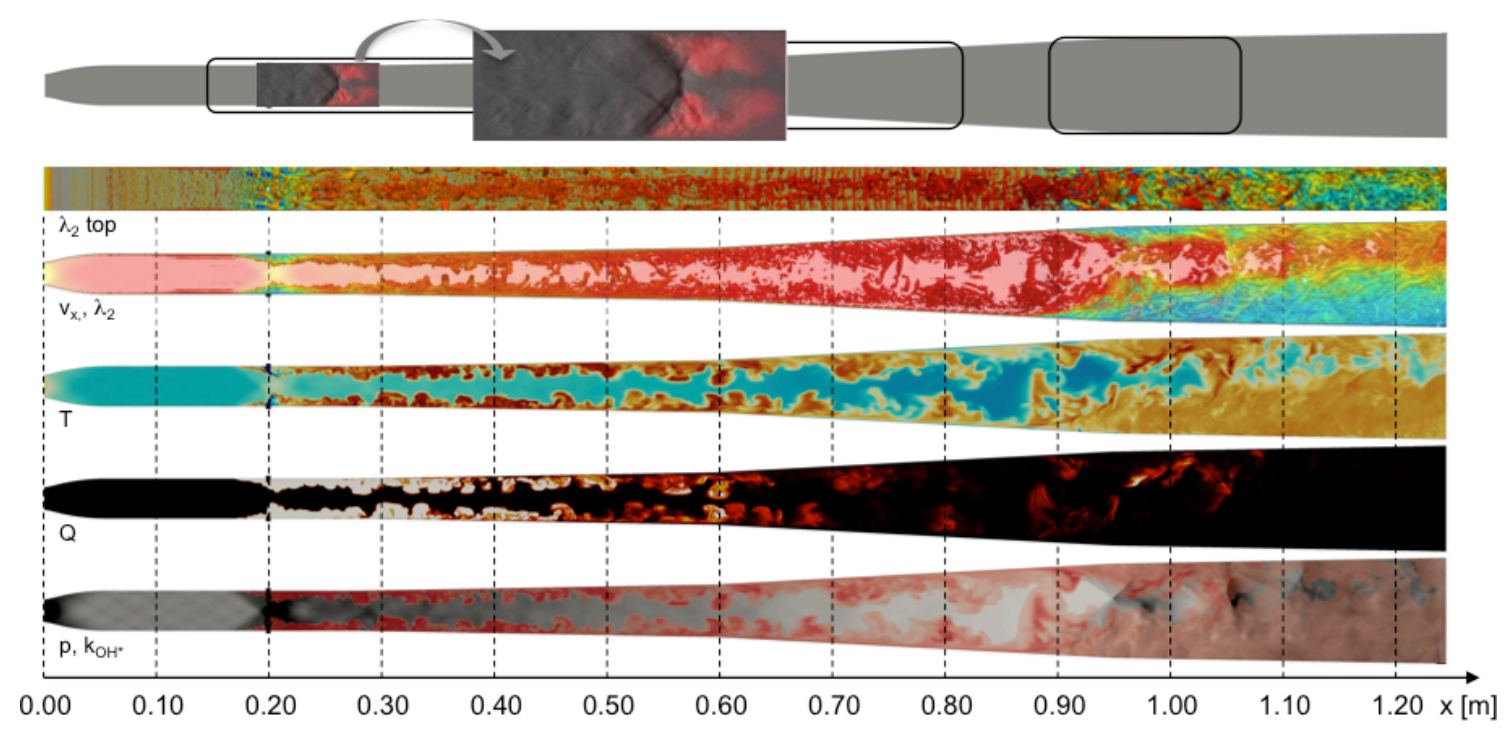

Figure 7. Combined experimental Schlieren and $\mathrm{OH}^{*}$ chemiluminescence (top) with computational images of the velocity, $\mathrm{v}_{\mathrm{x}}$, vorticity, $\lambda_{2}$, from above and from the side, and the temperature, $\mathrm{T}$, heat release, $\mathrm{Q}$, and $\mathrm{OH}^{*}$ photon emission rate, $\mathrm{k}_{\mathrm{OH}^{*}}$, for Case 4 .

To further elucidate the complex flow physics we next examine the perspective renderings of Cases $1,3 \mathrm{a}$ and 4 in figure 8 . These illustrate the flow in terms of iso-surfaces of the second invariant of the velocity-gradient tensor, $\lambda_{2}$, colored by the temperature, $\mathrm{T}$, filled contours of $\mathrm{T}$, and semi-transparent iso-surfaces of the pressure, p. For all cases, the boundary layer flow structures (longitudinal and hairpin vortices, and streaks) leading up to the injectors are similar, after which significant differences start to appear depending on $\mathrm{T}_{0}$. All cases also share the physics associated with the $\mathrm{H}_{2}$-rich plumes behind the bow- and lambda-shocks developing over the injectors. The plumes consists of a counter-rotating vortex pair along the average trajectory of each plume, starting at the leading edges of the jet shear-layers, and jet shear-layer vortices enfolding the jets, developing from Kelvin-Helmholtz instabilities in the jet-shear layers. Near the injectors, the jet shear-layer vortices typically form $S$-shaped side vortex arms and rollers, gradually developing $\Omega$-shaped vortex loops, and later longitudinal vortices. A horseshoe vortex develops in the region between the bow- and lambda shocks as a result of the flow stagnation and boundary-layer separation. Depending on the jet-to-freestream momentum ratio, $\mathrm{J}$, some $\mathrm{H}_{2}$ may be ingested into these horseshoe vortex systems that in turn merge with the corner vortices to form an complex vortex system developing parallel to the $\mathrm{H}_{2}$-plumes. Depending on $\mathrm{T}_{0}$ and the resulting difference in where combustion occurs, the flow and the vortex systems vary as the density, viscosity and baroclinic torque are influenced by the exothermicity and volumetric expansion. For example, the vortical structures of Cases $3 \mathrm{a}$ and 4 are much thicker than those of Case 1, resulting in different mixing and turbulence production. As observed in figures 4 to 7 , different combustion behaviors occur depending primarily on $T_{0}$. This is due primarily to the different ignition and flame stabilization mechanisms dominating the different cases. For Case 1 combustion occur just after separation, downstream of the $1^{\circ}$ to $3^{\circ}$ transition. This is due to that the ignition delay time, $\tau_{\text {ign }}$, is longer than the time it takes for the flow to traverse the two first combustor sections, i.e. $\tau_{\text {flow }} \approx \ell_{\text {comb }} / v$. For Case 3a combustion occur earlier, at the end of the first constant area combustor section, or in the beginning of the second combustor section. The mechanisms for ignition are more complicated but seem to be dominated by shock-induced ignition, after which reflected shocks impinge on the plume and horseshoe vortices, creating micro-explosions that in turn ignite the neighboring mixture. For Case 4 combustion occurs even earlier and seems more intense. In the experimental images combustion is shock-induced, and follows a lambda-shock, oscillating around $\mathrm{x} \approx 0.26$. In the numerical simulations combustion is also shock-induced, but occurs much earlier, at around $\mathrm{x}=0.22 \mathrm{~m}$. Here, the shock-train first ignites the $\mathrm{H}_{2}$ ingested in the horseshoe vortex system which then ignites the $\mathrm{H}_{2}$ in the plume. The $\mathrm{H}_{2}$ in the plume is also separately ignited by the shock train further downstream, around $\mathrm{x}=0.26 \mathrm{~m}$. This difference may be related to inconsistencies in the reaction mechanism, inconsistencies in the estimated wall temperatures used in the numerical simulations, or to some yet unknown factor. 


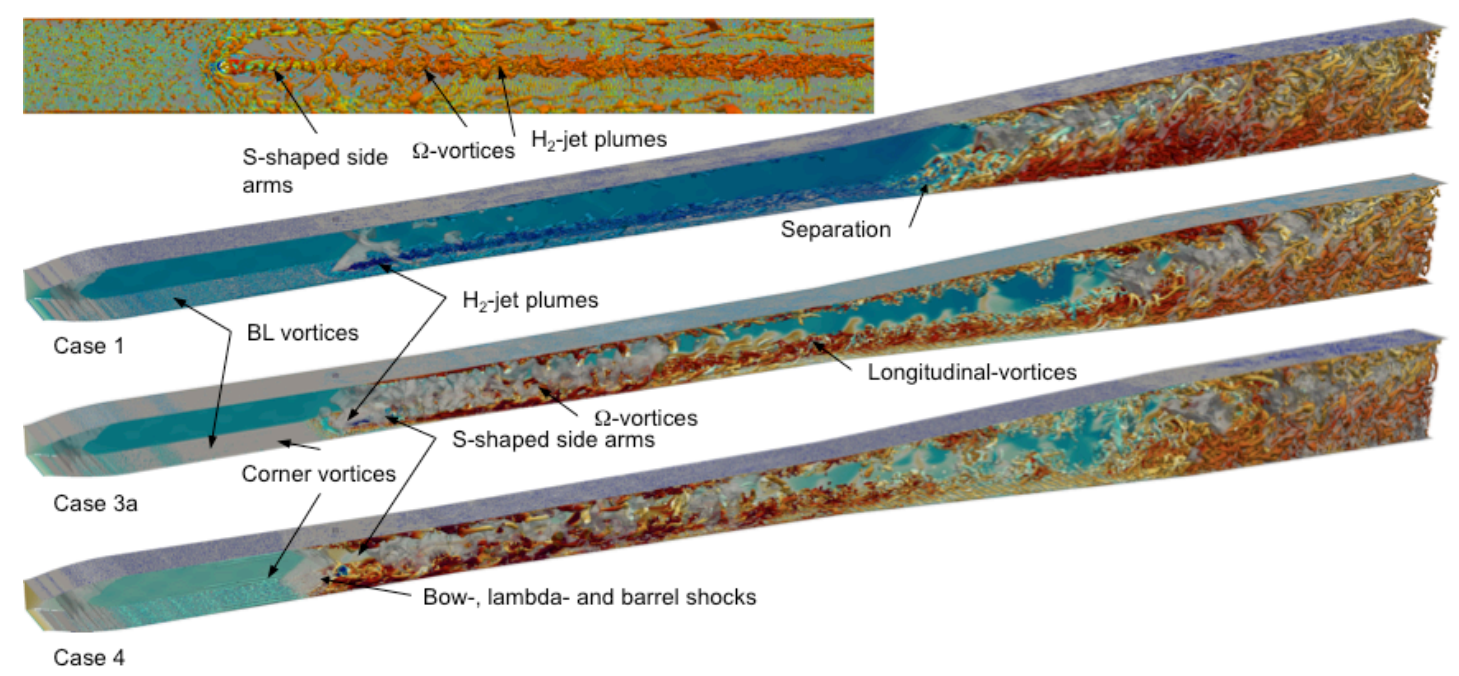

Figure 8. Computational images of superimposed vorticity, temperature and pressure for Case 1 (top), Case $3 \mathrm{a}$ (middle) and Case 4 (bottom). In the separate insert on the top, the vorticity for Case 1 is presented as viewed from above.

\section{V.C.Comparison of Wall-pressure and 1D Metrics in the LAPCAT-II Combustor}

Figure $9 \mathrm{a}$ and $9 \mathrm{~b}$ show profiles of the wall-pressure, $\mathrm{p}_{\mathrm{w}}$, from the experiments and the numerical simulations, and cross-sectional averaged profiles of the Mach number, Ma, normalized heat-release, $\mathrm{Q} / \mathrm{Q}_{\max }$, and streamthrust, $s / s_{\text {nozzle }}$, in which $\mathrm{s}=\mathrm{p}+\frac{1}{2} \rho \mathrm{v}_{\mathrm{x}}^{2}$. Regarding $\mathrm{p}_{\mathrm{w}}$ in figure $9 \mathrm{a}$ we notice that the numerical simulations generally capture the trends of the experiments well, but lack somewhat in detail. For Case 0 good agreement between simulation results and experimental data is observed. For Case $1 \mathrm{p}_{\mathrm{w}}$ increases slightly too early, suggesting too early combustion, possibly due to premature flow separation in the third combustor section. For Cases $3 \mathrm{a}$ and 4 both numerical simulations and experiments reveal a considerable increase in $\mathrm{p}_{\mathrm{w}}$ due to the volumetric expansion from the exothermicity. For Case 4a both the experiments and numerical simulations show a peak in $\mathrm{p}_{\mathrm{w}}$ at $\mathrm{x} \approx 0.26$. While the experimental $\mathrm{p}_{\mathrm{w}}$ profiles are nearly constant along the second combustor section, the $\mathrm{p}_{\mathrm{w}}$ profiles from the numerical simulations decrease somewhat along the second combustor section. This difference may be explained by a small step in the combustor geometry at $x \approx 0.60 \mathrm{~m}$ not included in the computational model. Moreover, the pressure recovery for $\mathrm{x}>0.80 \mathrm{~m}$ is reasonably well captured by all numerical simulations. Finally, comparison between measured and predicted $\mathrm{T}_{0}$ and $\mathrm{p}_{0}$ at $\mathrm{x} \approx 0.10 \mathrm{~m}$ shows excellent agreement for all cases indicating that the approach flow is well captured, and that the discrepancies between the experimental data and the numerical simulations are due to modeling deficiencies.
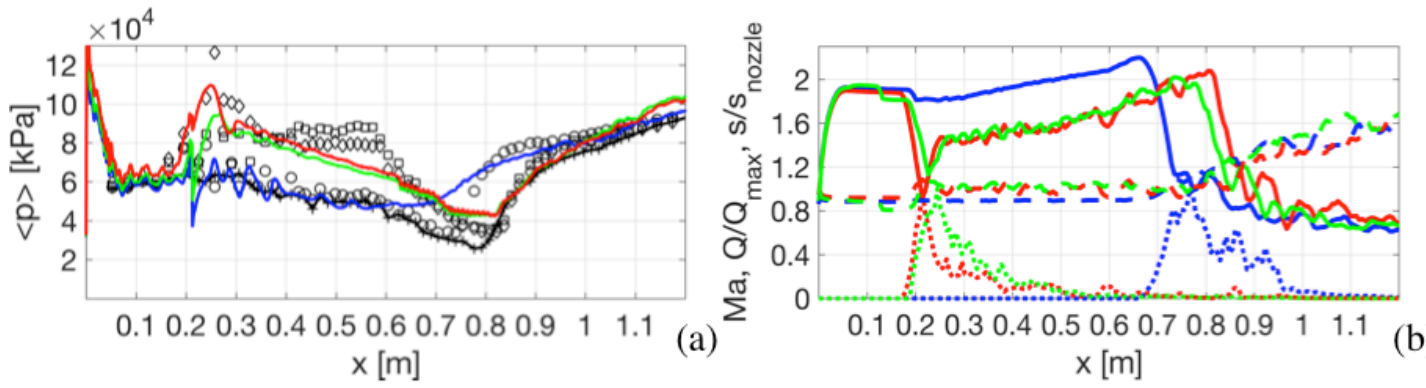

Figure 9. (a) Time-averaged wall-pressures, $\left\langle\mathrm{p}_{\mathrm{w}}\right\rangle$, along the lower combustor wall and (b) crosssecti-onally averaged Mach number, $\mathrm{Ma}$, and normalized heat-release, $\mathrm{Q} / \mathrm{Q}_{\max }$, and streamthrust,

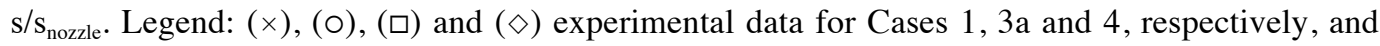
LES predictions for (-), (-), (-) and (-) Cases $0,1,3 \mathrm{a}$ and 4, respectively, on the 26 million cell grid. In (b) solid lines denote Ma, dotted lines denote $\mathrm{Q} / \mathrm{Q}_{\max }$ and dashed lines denote $\mathrm{s} / \mathrm{s}_{\text {nozzle }}$.

For the cross-sectional averaged profiles in figure $6 \mathrm{~b}$ we find that $\mathrm{Q} / \mathrm{Q}_{\max }$ occur in different locations for the different cases: For Case $1 \mathrm{Q} / \mathrm{Q}_{\max }$ occurs in the third (subsonic) combustor section, whilst for Cases $3 \mathrm{a}$ and 
$4, \mathrm{Q} / \mathrm{Q}_{\max }$ occur in the second (supersonic) combustor section, but with different axial distributions. Ma remains almost constant until $\mathrm{Q} / \mathrm{Q}_{\max }$ increases due to combustion after which Ma gradually increase for Cases $3 \mathrm{a}$ and 4 pending the fourth combustor section is reached, after which Ma decreases towards $\mathrm{Ma} \approx 0.80$. Moreover, $\mathrm{s} / \mathrm{s}_{\text {nozzle }}$ is nearly constant through the combustor for Case 1 but increases along the fourth combustor section. For Cases $3 \mathrm{a}$ and 4 a small increase in $\mathrm{s} / \mathrm{s}_{\text {nozzle }}$ is observed along the second and third combustor sections, after which $\mathrm{s} / \mathrm{s}_{\text {nozzle }}$ increase along the fourth combustor section.

\section{Concluding Remarks}

This paper describes a combined experimental and computational study of a supersonic flow and hydrogen-air combustion in the LAPCAT-II dual mode ramjet/scramjet combustor. The combustor consists of four sections with gradually increasing cross-sectional area, and experiments and LES have been performed for total temperatures of $1414 \mathrm{~K}<\mathrm{T}_{0}<1707 \mathrm{~K}$ at a total pressure of $\mathrm{p}_{0}=0.40 \mathrm{MPa}$ and an equivalence ratio of $\phi=0.15$. The diagnostics include reference measurements of $\mathrm{p}_{0}$ and $\mathrm{T}_{0}$ upstream of the combustor, wall-pressures at the combustor walls, and Schlieren and $\mathrm{OH}^{*}$ chemiluminescence imaging. The LES set-up consists of the whole combustor and the LES are performed using a compressible finite-rate chemistry LES model using a novel 22 step $\mathrm{H}_{2}$-air reaction mechanism suitable for the low-temperature chemistry of ignition. Boundary conditions for the LES are estimated from the experiments, and this constitutes probably the weakest link of the modeling approach as the wall temperatures are poorly known and the combustor walls can be considered rough due to the use of a thermal barrier coating.

For all cases, excellent agreement between predicted and measured reference values of $\mathrm{p}_{0}$ and $\mathrm{T}_{0}$ is found, ascertaining mutual agreement between the experiments and LES. For this $\mathrm{p}_{0}$ the combustor is overexpanded, and both the LES and experiments show that transition from supersonic to subsonic occur at the beginning of the fourth (and last) combustor section. By sweeping $\mathrm{T}_{0}$ different flow and combustion states are observed: For $\mathrm{T}_{0}=1414 \mathrm{~K}$ combustion occurs only in the separated region far downstream. For $\mathrm{T}_{0}=1505 \mathrm{~K}$ combustion starts between the first and second combustor sections, with experiments showing an abrupt combustion front and LES a less sharp but longitudinally oscillating combustion front. For $\mathrm{T}_{0}=1697 \mathrm{~K}$ combustion starts even earlier, with the LES predictions showing a somewhat to early, intermittent, combustion inception compared to the experimental data. Matching wall-pressure increases due to combustion are observed for the LES and the experiments. The LES and experiments both reveal a strong sensitivity of the combustor to variations in $\mathrm{T}_{0}$ reminiscent to turbulent supersonic hydrogen-air combustion. The LES results and the $\mathrm{OH}^{*}$ and Schlieren images are further utilized to describe the flow, mixing, self-ignition and turbulent combustion, and the influence of increasing $\mathrm{T}_{0}$.

\section{Acknowledgement}

The authors acknowledge the support of ONERA and FOI, respectively; VS was also supported by the Grant of the Ministry of Education and Science of the Russian Federation (Contract No. 14.G39.31.0001 of 13.02.2017).

\section{References}

[1] Kanda T \& Kudo K.; 2003, "Conceptual Study of a Combined-Cycle Engine for an Aerospace Plane”, J. Prop. and Power, 19, pp. 859.

[2] Thomas S., 2012, "TBCC Technical Challenge Overview”, 2012 NASA Technical Conference, March 13-15, 2012 Cleveland, $\mathrm{OH}$.

[3] Heiser W.H \& Pratt D.T.; 1994, "Hypersonic Airbreathing Propulsion”, AIAA Education Series.

[4] Sullins G.A.; 1993, "Demonstration of Mode Transition in a scramjet Combustor", J. Prop. Power, 9, p 515.

[5] Dessornes O. \& Scherrer D.; 2005, "Tests of the JAPHAR Dual Mode Ramjet Engine", Aerospace Science and Technology, 9, p 211.

[6] Kato K., Kanda T., Kobayashi K., Kudo K. \& Murakami A.; 2006, "Downstream Ramjet-Mode Combustion in a Dual-Mode Scramjet Engine”, J.Prop. Power, 22, p 511.

[7] Micka D.J. \& Driscoll J.F.; 2009, "Combustion Characteristics of a Dual-Mode Scramjet Combustor with Cavity Flameholder”, Proc. Comb. Inst. 32, p 2397.

[8] Cabell K., Hass N., Storch A. \& Gruber M.; 2011, "HIFiRE Direct-Connect Rig (HDCR) Phase I Scramjet Test Results from the NASA Langley Arc-Heated Scramjet Test Facility”, AIAA 2011-2248. 
[9] Fotia M.L.; 2015, "Mechanics of Combustion Mode Transition in a Direct-Connect Ramjet-Scramjet Experiment”. J. Prop. Power, 31, p 69.

[10] Aguilera C. \& Yu K.H.; 2017, "Scramjet to Ramjet Transition in a Dual-mode Combustor with Finguided Injection”, Proc. Comb. Inst., 36, p 2911.

[11] Baurle R.A. \& Eklund D.R.; 2002. "Analysis of Dual-Mode Hydrocarbon Scramjet Operation at Mach 4-6.5", J. Prop. Power, 18, p 990

[12] Vyas M.A., Engblom V.A., Georgiadis N.J., Trefny C.J.\& Bhagwandin V.A.; 2010, ”Numerical Simulation of Vitiation Effects on a Hydrogen-Fueled Dual-Mode Scramjet, AIAA-2010-1127.

[13] Quinlan J., McDaniel J.C., Drozda T.G., Lacaze G. \& Oefelein J.C.; 2014, "A Priori Analysis of Flamelet-based Modeling for a Dual-Mode Scramjet Combustor", AIAA 2014-3743.

[14] Fulton J., Edwards J., Hassan H., Rockwell R., Goyne C., McDaniel J., Smith C., Cutler A., Johansen C., Danehy P. \& Kouichi T.; 2012, "Large-Eddy/Reynolds-Averaged Navier Stokes Simulation of a Dual-Mode Scramjet Combustor", AIAA 2012-0115

[15] Bermejo-Moreno I., Larsson J., Bodart J. \& Vicquelin R.; 2013, "Wall-Modeled Large-Eddy Simulations of the HIFiRE-2 Scramjet", CTR Annual Research Briefs, p 3.

[16] Fulton J.A., Edwards J.R., Hassan H.A., McDaniel J.C., Goyne C.P., Rockwell R.D., Cutler A.D., Johansen C.T. \& Danehy P.M.; 2014, "Large-Eddy/Reynolds-Averaged Navier-Stokes Simulations of Reactive Flow in Dual-Mode Scramjet Combustor", J. Prop. and Power, 30, pp. 558.

[17] Lacaze G., Vane Z.P., Oefelein J.C.; 2016, "Large Eddy Simulation of the HIFiRE Direct Connect Rig Scramjet Combustor", SAND2016-12566C

[18] Huang W. \& Yan L.; 2016, "Numerical Investigation on the Ram-Scram Transition Mechanism in a Strut-based Dual-Mode Scramjet Combustor", Int. J. Hydrogen Energy, 41, p 4799.

[19] Vincent-Radonnier A., Moule Y.\& Ferrier M.; 2014, "Combustion of Hydrogen in Hot Air Flows within LAPCAT-II Dual Mode Ramjet Combustor at Onera-LAERTE Facility - Experimental and Numerical Investigati-on", AIAA 2014-2931.

[20] Menon S. \& Fureby C.; 2010, “Computational Combustion”, In Encyclopedia of Aerospace Engineering, Eds. Blockley R. \& Shyy W., John Wiley \& Sons.

[21] Echekki T.\& Mastorakos E.; 2011, “Turbulent Combustion: Concepts, Governing Equations and Modeling Strategies" in Turbulent Combustion Modeling: Advances, New Trends and Perspectives", Springer, Netherlands.

[22] Giacomazzi E., Picchia F.R. \& Arciacono N.; 2007, "On the Distribution of Lewis and Schmidt Numbers in Turbulent Flames", $30^{\text {th }}$ Italian Meeting on Combustion, Ischia, Italy.

[23] Bensow R. \& Fureby C.; 2007, "On the Justification and Extension of Mixed Models in LES”, J. Turb. 8, N54, p. 1.

[24] Fureby C.; 2009, "LES Modeling of Combustion for Propulsion Applications", Phil. Trans. R. Soc. A, 367, p 2957.

[25] Sabelnikov V. \& Fureby C.; 2013, "LES Combustion Modeling for High Re Flames using a Multi-Phase Analogy", Comb. Flame, 160, p 83.

[26] Tanahashi M., Fujimura M. \& Miyauchi T.; 2000, "Coherent Fine Scale Eddies in Turbulent Premixed Flames", Proc. Comb. Inst. 28, p 5729.

[27] Nogenmyr K-J., Fureby C., Bai., X.S., Petersson P. \& Linné M.; 2009, "Large Eddy Simulation and Laser Diagnostic Studies on a Low Swirl Stratified Premixed Flame”, Comb. Flame, 156, p 25.

[28] Fedina E. \& Fureby C.; 2011, "A Comparative Study of Flamelet and Finite Rate Chemistry LES of an Axisymmetrc Dump Combustor”, J. Turb. 12, N24.

[29] Zettervall, N., Nordin-Bates K., Heimdal-Nilsson E. \& Fureby C., 2015, "Large Eddy Simulation (LES) of a Premixed Bluff Body Stabilized Flame using Global and Skeletal Reaction Mechanisms", Comb. Flame, 179, p 1 .

[30] Fedina E., Fureby C., Bulat G. \& Maier W.; 2017, “Assessment of Finite Rate Chemistry Large Eddy Simulation Combustion Models”, Flow, Turb. and Comb., 99, p 385.

[31] Fureby C., Nordin-Bates K., Petterson K., Bresson A. \& Sabelnikov V.; 2014, "A Computational Study of Supersonic Combustion in Strut Injector and Hypermixer Flow Fields”, Comb. Inst. 35, p 2127.

[32] Nordin-Bates K., Fureby C., Karl S. \& Hannemann K.; 2017, "Understanding Scramjet Combustion using LES of the HyShot II Combustor”, Proc. Comb. Inst., 35, p 2893.

[33] Weller H.G., Tabor G., Jasak H. \& Fureby C.; 1997, “A Tensorial Approach to CFD using Object Oriented Techniques“, Comp. in Physics, 12, p 629.

[34] Drikakis D., Fureby C., Grinstein F.F. \& Liefendahl M.; 2007, "ILES with Limiting Algorithms", In Implicit Large Eddy Simulation: Computing Turbulent Fluid Dynamics, Eds. Grinstein F.F., Margolin L. \& Rider B., Cambridge University Press, p 94. 
[35] Hairer E. \& Wanner G.; 1991, "Solving Ordinary Differential Equations”, II: Stiff and Differential-Algebraic Problems, $2^{\text {nd }}$ Ed., Springer Verlag.

[36] Celik I., Cehreli Z. N., \& Yavuz I.; 2005, "Index of Resolution Quality for Large Eddy Simulations", ASME,

J. Fluids Engineering, 127, p 949.

[37] Poinsot T.J. \& Lele S.K.; 1992, "Boundary Conditions for Direct Simulations of Compressible Viscous Flows", J. Comp. Phys., 101, p 104.

[38] Fureby C., Alin N., Wikström N., Menon S., Persson L., \& Svanstedt N.; 2004, “On Large Eddy Simula-tions of High Re-number Wall Bounded Flows", AIAA.J. 42, p 457.

[39] Larsson A., Zettervall N., Hurtig T., Nilsson E.J.K., Ehn A., Petersson P., Alden M., Larfeldt J. \& Fureby C.; 2017, "Skeletal Methane-Air Reaction Mechanism for Large Eddy Simulation of Turbulent Microwave-Assisted Combustion”, Energy Fuels, 31, p 1904.

[40] O'Conaire M., Curran H.J., Simmie J.M., Pitz W.J. \& Westbrook C.K.; 2004 “A Comprehensive Modeling Study of Hydrogen Oxidation”, 2004, Intersience.wiley.com

[41] Alekseev V.A., Christensen M. \& Konnov A.A.; 2015, "The Effect of Temperature on the Adiabatic Burning Velocities of Diluted Hydrogen Flames: A Kinetic Study using an Updated Mechanism”, Comb. Flame, 162, p. 1884.

[42] Davis S.G., Joshi A.V. \& Wang H.; 2005, “An Optimized Kinetic Model of $\mathrm{H}_{2} / \mathrm{CO}$ Combustion”, Proc. Comb. Inst, 30, p. 1283.

[43] Sánchez A.L. \& Williams F.A.; 2014, "Recent Advances in Understanding of Flammability Characteristics of Hydrogen", Progress in Energy Comb. Sci., 41, p. 1.

[44] Jachimowski C.A.; 1988, "An Analytical Study of the Hydrogen-Air Reaction Mechanism with Application to Scramjet Combustion", NASA Technical Paper 2791.

[45] Davidenko D.M., Gokalp I., Dufour E. \& Magre P.; 2003, "Numerical Simulation of Hydrogen Supersonic Combustion and Validation of Computational Approach", AIAA 2003-7003.

[46] Marinov N.M., Westbrook C.K. \& Pitz W.J.; 1995, "Detailed and Global Chemical Kinetics Model for Hydrogen”, $8^{\text {th }}$ Int. Symp. on Transport Properties, San Fransisco, CA, USA.

[47] Hu E., Huang Z., He J. \& Miao H.; 2009, "Experimental and Numerical Study on Laminar Burning Velocities and Flame Instabilities of Hydrogen-Air Mixtures at Elevated Pressures and Temperatures", Int. J. Hydrogen Energy, 34, p 8741.

[48] Aung K.T., Hassan M.I. \& Faeth G.M.; 1997, "Flame Stretch Interactions of Laminar Premixed Hydrogen/air Flames at Normal Temperature and Pressure”, Comb. Flame, 109, p 1.

[49] Kwon O.C. \& Faeth G.M.; 2001, "Flame/Stretch Interactions of Premixed Hydrogen-Fueled Flames: Measurements and Predictions", Comb. Flame, 124, p 590.

[50] Lamoureux N., Djebaili-Chaumeix N., Paillard C.-E.; 2003, "Laminar Flame Velocity Determination for $\mathrm{H}_{2}$-air-He- $\mathrm{CO}_{2}$ Mixtures using the Spherical Bomb Method", Exp. Therm. Fluid Sci., 27, p 385.

[51] Burke M.P., Chen Z., Ju Y. \& Dryer F.L.; 2009, "Effect of Cylindrical Confinement on the Determination of Laminar Flame Speeds using Outwardly Propagating Flames”, Comb. Flame, 156, p 771.

[52] Pareja J., Burbano H.J. \& Ogami Y.; 2010, "Measurements of the Laminar Burning Velocity of Hydrogen-Air Premixed Flames”, Int. J. Hydrogen Energy, 35, p 1812.

[53] Krejci M.C., Mathieu O., Vissotski A.J., Ravi S., Sikes T.G., Petersen E.L., A., Metcalfe W. \& Curran H.J.; 2013, J. Eng. Gas Turbines Power, 135, p 021503.

[54] Hu E, Pan L., Gao Z., Lu X., Meng X. \& Huang Z.; 2016, "Shock Tube Study on Ignition Delay of Hydrogen and Evaluation of Various Kinetic Models”, Int. J. Hydrogen Energy, 41, p. 13261.

[55] Samuelsen S., McDonell V., Greene M. \& Beerer D.; 2006, "Correlation of Ignition Delay with Natural Gas and IGCC type Fuels", 2006, DOE Award Number: DE-FC26-02NT41431.

[56] Blumenthal R.; 1996, "Experimentelle Untersuchung und Numerische Simulation der Selbstzuendung von Kraftstoff/Luft-Gemischen im Stosswellenrohr unter Beruecksichtigung stroemungsmechanischer Einfluesse", Doc-toral Thesis, Institut für Allgemeine Mechanik, RWTH Aachen, Germany.

[57] Craig R.R.; 1966, "A Shock Tube Study of the Ignition Delay of Hydrogen-Air Mixtures near the Second Explosion Limit”, Report AFAPL-TR-66-74.

[58] Slack M.W.; 1977, "Rate Coefficient for $\mathrm{H}+\mathrm{O}_{2}+\mathrm{M}=\mathrm{HO}_{2}+\mathrm{M}$ Evaluated From Shock Tube Measurements of Induction Times", Comb. Flame, 28, pp. 241.

[59] Beerer D.J. \& McDonell, V.G.; 2008, “Autoignition of Hydrogen and Air Inside a Continuous Flow Reactor With Application to Lean Premixed Combustion”, J. Eng. for Gas Turbines and Power, 130, p 051507.

[60] Snyder A.D., Robertson J., Zanders D.L. \& Skinner G.B.; 1965, "Shock Tube Studies of Fuel-Air Ignition Characteristics", Report AFAPL-TR-65-93-1965

[61] Wang B.L., Olivier H. \& Groenig H.; 2003, "Ignition of Shock-Heated H2-Air-Stream Mixtures”, Comb. 
Flame, 133, p 93.

[62] Voevodski V.V. \& Soloukhin R.I.; 1965, "On the mechanism and explosion limits of hydrogen-oxygen chain self-ignition in shock waves", Proc. Comb. Inst., 10, p 279.

[63] Meyer J. \& Oppeneheim A.K., 1971, "On the Shock-Induced Ignition of Explosive Gases”, Proc. Comb. Inst. 13, p 1153.

[64] Nori V. \& Seitzman J.; 2008, "Evaluation of Chemiluminescence as a Combustion Diagnostic under Varying Operating Conditions", AIAA 2008-0953.

[65] Lock A.J., Briones A.M., Qin X., Aggarwal S.K, Puri I.K., Hegde U.; 2005, "Liftoff characteristics of partially premixed flames under normal and microgravity conditions", Comb. Flame, 143, p 159. 